Erratum

\title{
Erratum: A Novel Human-Like Collagen Hydrogel Scaffold with Porous Structure and Sponge-Like Properties. Polymers, 2017, 9, 638
}

\author{
Xi Song ${ }^{1,2}$, Chenhui Zhu ${ }^{1,2}$, Daidi Fan ${ }^{1,2, *}$, Yu Mi ${ }^{1,2, *}$, Xian Li ${ }^{1,2}$ (D), Rong Zhan Fu ${ }^{1,2}$, \\ Zhiguang Duan ${ }^{1,2}$, Ya Wang ${ }^{1,2}$ and Rui Rui Feng ${ }^{1,2}$ \\ 1 Shaanxi Key Laboratory of Degradable Biomedical Materials, School of Chemical Engineering, \\ Northwest University, 229 North Taibai Road, Xi'an 710069, China; songxi93@126.com (X.S.); \\ zch@nwu.edu.cn (C.Z.); li_xian1214@163.com (X.L.); rongzhanfu@nwu.edu.cn (R.Z.F.); \\ duan11170@163.com (Z.D.); lanmao1998@163.com (Y.W.); alice2017innu@163.com (R.R.F.) \\ 2 Shaanxi R\&D Center of Biomaterials and Fermentation Engineering, School of Chemical Engineering, \\ Northwest University, 229 North Taibai Road, Xi'an 710069, China \\ * Correspondence: fandaidi@nwu.edu.cn (D.F.); mi_yu@nwu.edu.cn (Y.M.); Tel.: +86-29-8830-5118 (D.F.) \\ Received: 27 February 2018; Accepted: 5 March 2018; Published: 12 March 2018
}

The authors wish to make a change to the published paper [1]. In Section 2.2, "HLC $(120 \mathrm{~g} / \mathrm{mL})$ and BSA $(80 \mathrm{~g} / \mathrm{mL})$ " has been changed to "HLC $(120 \mathrm{mg} / \mathrm{mL})$ and BSA $(80 \mathrm{mg} / \mathrm{mL})$ ". The mistake was due to the authors' oversight. To avoid misleading readers, we would like to update the data in the article. The authors apologize for any inconvenience this may have caused.

The manuscript will be updated and the original will remain online on the article webpage http:/ / www.mdpi.com/2073-4360/9/12/638.

\section{Reference}

1. Song, X.; Zhu, C.; Fan, D.; Mi, Y.; Li, X.; Fu, R.Z.; Duan, Z.; Wang, Y.; Feng, R.R. A Novel Human-Like Collagen Hydrogel Scaffold with Porous Structure and Sponge-Like Properties. Polymers 2017, 9, 638. [CrossRef]

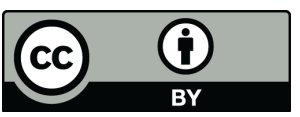

(C) 2018 by the authors. Licensee MDPI, Basel, Switzerland. This article is an open access article distributed under the terms and conditions of the Creative Commons Attribution (CC BY) license (http:/ / creativecommons.org/licenses/by/4.0/). 